\title{
Gross Motor Delay
}

National Cancer Institute

\section{Source}

National Cancer Institute. Gross Motor Delay. NCI Thesaurus. Code C116601.

Abnormally late development of the coordination of the muscles, bones, and/or nerves

that produces whole body and large muscle group movements. 